\title{
Design and Application of a Single Phase Multilevel Inverter Suitable for using as a Voltage Harmonic Source
}

\author{
Ersoy Beser ${ }^{\dagger}$, Birol Arifoglu*, Sabri Camur*, and Esra Kandemir Beser* \\ $\dagger *$ Dept. of Electrical Eng., Kocaeli University, Kocaeli, Turkey
}

\begin{abstract}
This paper presents a single phase multilevel inverter for using as a voltage harmonic source. First, a single phase multilevel inverter system is presented and the structural parts of the inverter are described. In order to obtain multilevel output voltage waveforms, a switching strategy based on calculating switching angles is explained and an improved formula for determining switching angles is given. Simulation and experimental results of multilevel voltage waveforms are given for 15,31 and 127 levels. The proposed topology does not only produce output voltages with low THD values. It also produces the required harmonic components on the output voltage. For this purpose, equations for switching angles are constituted and the switching functions are obtained. These angles control the output voltage as well as provide the required specific harmonics. The proposed inverter structure is simulated for various functions with the required harmonic components. The THD values of the output voltage waves are calculated. The simulated functions are also realized by the proposed inverter structure. By using a harmonic analyzer, the harmonic spectrums, which belong to the output voltage forms, are found and the THD values are measured. Simulation and experimental results are given for the specific functions. The proposed topology produces perfectly suitable results for obtaining the specific harmonic components. Therefore, it is possible to use the structure as a voltage harmonic source in various applications.
\end{abstract}

Key Words: Harmonic, Harmonic components, Harmonic source, Multilevel inverter, Voltage active filter

\section{NOMENCLATURE}

$V_{d}$

voltage of the first level module

$V_{\max }$

$V_{\text {ref }}$

$V_{0}$

$V_{f}$

$V_{h} \quad$ peak voltage of the $\mathrm{h}^{\text {th }}$ harmonic component

$V_{d c} \quad$ dc component value of the output voltage

$n \quad$ number of output voltage levels

$m \quad$ number of level modules

$r \quad$ number of switches

$\theta_{j} \quad$ switching angle

$\varphi_{h} \quad$ phase angle

$\omega \quad$ angular speed

$t_{\max }$ maximum value of the sample time

$t_{\text {sample }}$ value of the sample time

$f_{f} \quad$ frequency of the fundamental harmonic component

$Q_{(k-1)}(k-1)^{t h}$ switching signal

\section{INTRODUCTION}

Power electronic inverters have been used in various applications recently. Inverters have become a necessity for many implementations in industrial areas. So, numerous configurations and switching strategies have been presented and discussed extensively.

Particularly, multilevel inverters have received increasing interest for power conversion in high-power applications due to their lower harmonics, higher efficiency and lower voltage stress compared to two-level inverters [1]. Various topologies for multilevel inverters have been introduced and widely studied [1]- [23]. The most considerable of these topologies are the diode clamped [neutral-point clamped (NPC)] inverter [7], the capacitor clamped (flying capacitor) inverter [8] and the cascaded H-bridge inverter with separated dc sources [9].

Multilevel inverters generate a staircase waveform. By increasing the number of output levels, the output voltages have more steps and harmonic content on the output voltage and the THD values are reduced [10]. Therefore, they produce highquality output voltage by increasing the level number.

However, in some conditions, the harmonic components on an output voltage wave are required for special applications. For example harmonic components are needed for researching the effects of harmonic components on transformers, induction machines, capacitors and they are used in transmission lines to observe their results. Specific harmonic components are also

Manuscript received Oct. 16, 2009; revised Jan. 14, 2010

†Corresponding Author: ersoybeser@ hotmail.com

Tel: +902623033490, Kocaeli University

* Dept. of Electrical Eng., Kocaeli University, Turkey 


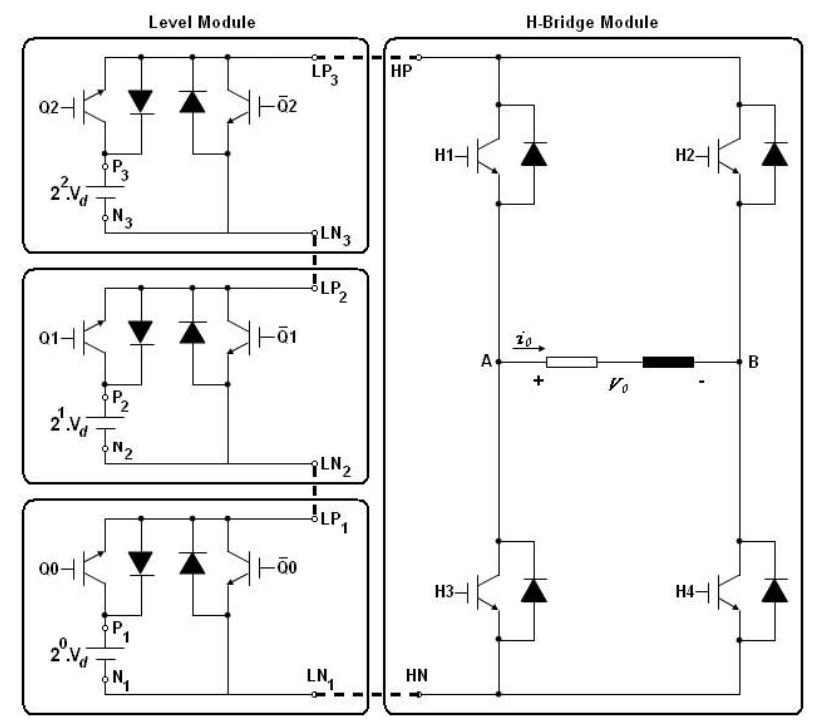

Fig. 1. Configuration of the proposed single phase multilevel inverter system for 15 levels.

required for voltage active filter applications.

This paper presents the performance of a single phase multilevel inverter for using as a voltage harmonic source. The structure of the proposed inverter is different from some inverter types in literature [11]. The level number can be easily increased. As a result, voltage stress is reduced and more sinusoidal shaped output voltage waves can be obtained. In addition, the required harmonic components on an output voltage wave can be obtained suitably for the objectives of this study. To accomplish this, a method for finding the switching equations is explained. The proposed inverter is simulated for various specific functions including harmonic content. The validity of the proposed method is verified through an experimental study. The proposed inverter gives perfect performance for obtaining the required harmonic components. Therefore, its use as a voltage harmonic source is highly efficient.

\section{Proposed Multilevel InVerter System And \\ Switching Strategy For Multilevel Voltage WAVES}

In this study, a single phase multilevel inverter system is proposed. The principle of the proposed method will be explained for a 15-level inverter. However, the structure can be easily adapted to any number of levels. The configuration of the inverter structure is shown in Fig.1.

The proposed multilevel inverter structure consists of two basic parts. The parts are classified as Level and H-Bridge Modules. The most remarkable feature of the system is its ease of expansion. By increasing the number of level modules and connecting them cascaded, the inverter system can expand and the voltage level number can be easily increased.

The Level Module consists of two semiconductor switching devices and a dc source. The voltage of the dc source is expressed by $k$ and $V_{d}$ as $2^{(k-1)} \cdot V_{d}$. Generally $V_{d}$ is expressed as:

$$
\begin{aligned}
V_{d} & =\frac{2 \cdot V_{\max }}{n-1} \\
k & =1,2,3, \ldots, m .
\end{aligned}
$$

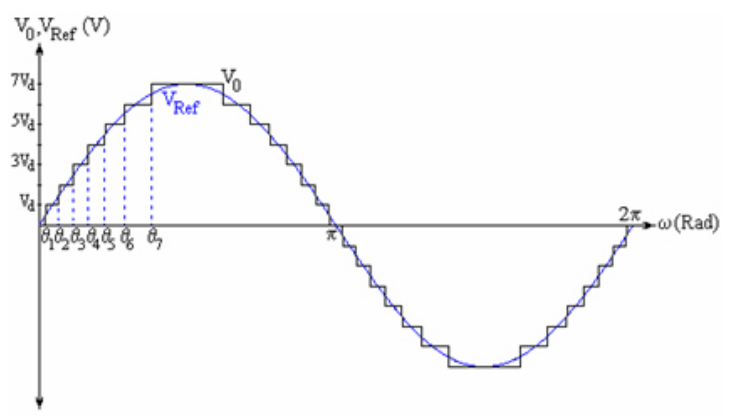

Fig. 2. 15-level output voltage $\left(V_{0}\right)$, reference voltage wave $\left(V_{R e f}\right)$ and switching angles $\left(\theta_{1}, \theta_{2}, \theta_{3}, \ldots \theta_{7}\right)$.

The number of switches and output levels related to the number of cascaded level modules are given in Table 1.

As it can be seen from Table 1, in the event of using four level modules, a 31-level output voltage form is obtained. However this level number is the maximum value for four level modules. By using four level modules in the inverter structure, $17,19,21, \ldots, 29$-level voltage waves can be obtained addition to the 31-level output. Therefore, the output level numbers in the table are the maximum values for the given level module number.

TABLE I

NUMBER OF SWITCHES AND OUTPUT LEVELS RELATED TO NUMBER OF

\begin{tabular}{|c|c|c|}
\hline \multirow{2}{*}{$\begin{array}{c}\text { Cascaded } \\
\text { Level Modules }\end{array}$} & \multirow{2}{*}{\begin{tabular}{|c} 
DC Source \\
Ratio
\end{tabular}} & Output Level (n) \\
\hline & & Number of Switches (r) \\
\hline \multirow{2}{*}{ LM1 } & \multirow{2}{*}{$1 V_{d}$} & \begin{tabular}{|c|}
3 \\
\end{tabular} \\
\hline & & 6 \\
\hline \multirow{2}{*}{ LM2 } & \multirow{2}{*}{$2 V_{d}$} & 7 \\
\hline & & 8 \\
\hline \multirow{2}{*}{ LM3 } & \multirow{2}{*}{$4 V_{d}$} & 15 \\
\hline & & 10 \\
\hline \multirow{2}{*}{ LM4 } & \multirow{2}{*}{$8 V_{d}$} & 31 \\
\hline & & 12 \\
\hline \multirow{2}{*}{ LM5 } & \multirow{2}{*}{$16 V_{d}$} & 63 \\
\hline & & 14 \\
\hline \multirow{2}{*}{ LM6 } & \multirow{2}{*}{$32 V_{d}$} & 127 \\
\hline & & 16 \\
\hline$:$ & $:$ & $:$ \\
\hline$:$ & : & : \\
\hline \multirow{2}{*}{ LM m } & \multirow{2}{*}{$2^{(m-1)} V_{d}$} & $2^{(m+1)}-1$ \\
\hline & & $2 m+4$ \\
\hline
\end{tabular}
CASCADED LEVEL MODULES (LM)

The number of output level $(n)$ and the number of switches $(r)$ are expressed as follows:

$$
\begin{aligned}
& n=2^{(m+1)}-1 \\
& r=2 m+4 .
\end{aligned}
$$

The switching strategy in the proposed method is to generate gate signals by calculating switching angles [20]. The required switches are switched alternately and multilevel output voltage wave is obtained by using the calculated angle values and the known frequency. For calculating switching angles, a simple method is developed for the proposed inverter topology. The 


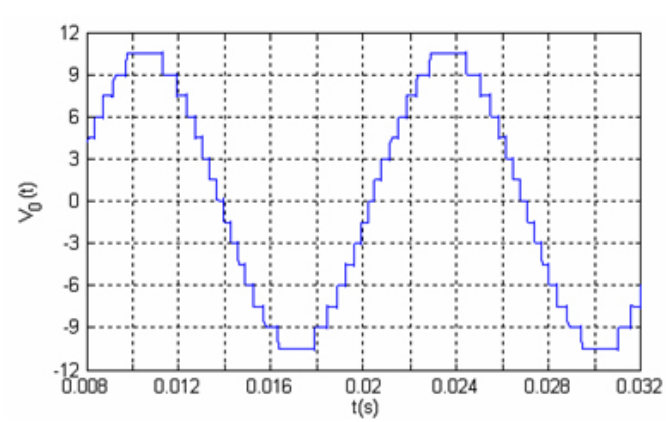

(a) Simulation, 15-level

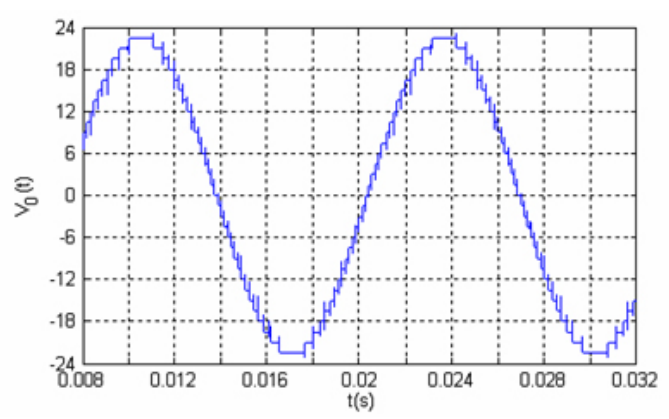

(c) Simulation, 31-level

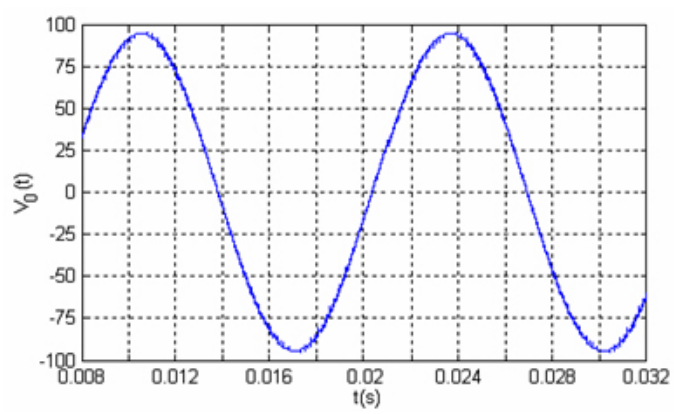

(e) Simulation, 127-level

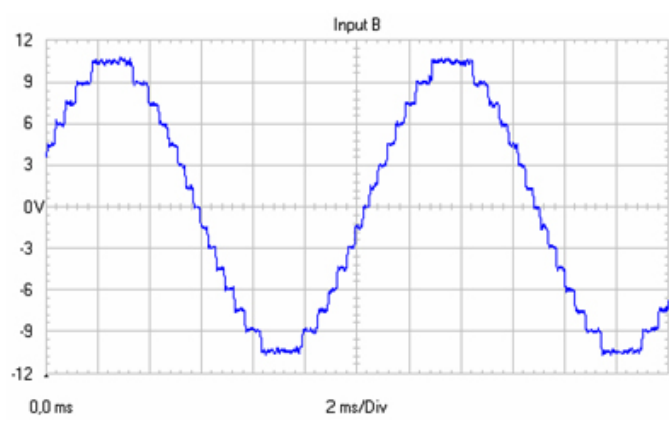

(b) Experimental, 15-level

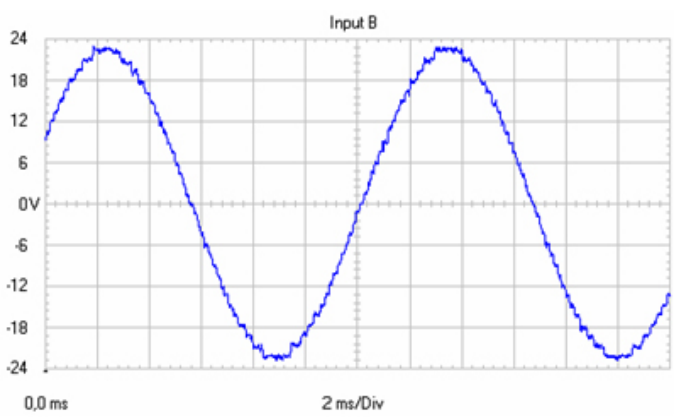

(d) Experimental, 31-level

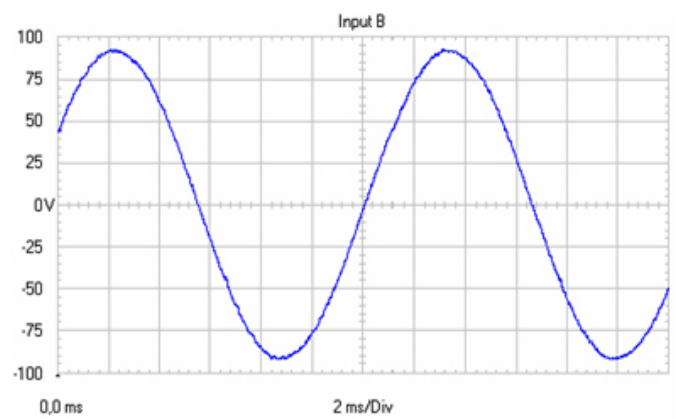

(f) Experimental, 127-level

Fig. 3. Simulation and experimental results of multilevel output voltage $\left(V_{0}\right)$ for resistive loads in the proposed multilevel inverter.

formula for this method is given as follows:

$$
\begin{aligned}
& \theta_{j}=\sin ^{-1}\left(\frac{2 j-1}{n-1}\right) \\
& j=1,2,3, \ldots,\left(\frac{n-1}{2}\right) .
\end{aligned}
$$

For instance, the switching angles $\theta_{1}, \theta_{2}, \theta_{3}, \theta_{4}, \theta_{5}, \theta_{6}$ and $\theta_{7}$ can be calculated by using equations (5) and (6) for a single phase 15-level inverter topology.

The output voltage and the reference voltage waves according to the calculated switching angles are illustrated in Fig.2 for a 15-level topology.

In order to increase the output voltage levels, level modules are increased and various output levels can be obtained in respect to equation (3). This approach can be easily applied to any number of levels. In this case, switching angles should be calculated for each voltage level number.

In Fig.3 simulation and experimental results of output voltage waves in the proposed multilevel inverter are given for 15, 31 and 127-level voltage waveforms.
The output voltages can have more steps by increasing the number of output levels. In this condition, the shape of output voltage converges more to a sinusoidal waveform and the THD value of output voltage is considerably reduced.

Through simulations and experiments, it can be seen that the proposed inverter topology generates a high-quality output voltage waveform. By increasing the level number, the THD values of the output voltage decrease even for resistive loads. The switching strategy is simple and switching angles can be easily obtained by using the formula. The ease of expansion for the proposed multilevel inverter system makes it easy to increase the number of output levels. By increasing the level number and producing a multilevel voltage wave, $d v / d t$ stresses imposed on power-switching devices are reduced in the proposed topology.

\section{Determining Switching Angles For Obtaining HARMONIC COMPONENTS}

The proposed multilevel inverter produces multilevel output voltages with low harmonic content as mentioned in section 


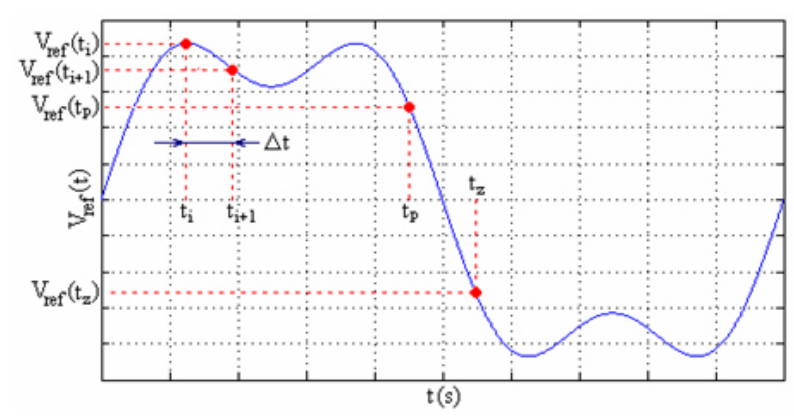

Fig. 4. A sample reference output voltage wave.

2. The proposed structure is also capable of producing the required harmonic components on the output voltage so that it can be used as a voltage harmonic source. In order to obtain an output voltage with harmonic content, first, the required harmonic components are determined and the equation for the reference voltage is obtained as follows:

$$
V_{\text {ref }}=\frac{V_{d c}}{2}+\sum_{h=1}^{\infty} V_{h} \sin \left(h \omega t+\varphi_{h}\right) .
$$

In equation (8), a sample reference function is given and the output voltage wave of the sample function is illustrated in Fig.4.

$$
V_{\text {ref }}=V_{1} \sin \omega t+V_{3} \sin 3 \omega t .
$$

$\Delta t$ seen in Fig.4 gives the sample time of switching signals. When a smaller value is chosen, the output voltage more closely resembles the reference signal. The sample time is related to the frequency of the fundamental harmonic component and the level module number. In equation (9) the maximum value of sample $\left(t_{\max }\right)$ time, which is related to the fundamental frequency and the level module number, is given. During operation, the sample time $\left(t_{\text {sample }}\right)$ should be chosen smaller than $t_{\max }$ for obtaining an output voltage that is similar to the reference signal.

$$
\begin{aligned}
t_{\max } & =\sin ^{-1}\left(\frac{1}{2^{(m+1)}-2}\right) \cdot\left(2 \pi f_{f}\right)^{-1} \\
t_{\text {sample }} & =\Delta t=t_{i+1}-t_{i} \\
t_{\text {sample }} & <<t_{\max } .
\end{aligned}
$$

$V_{\text {ref }}$ value at any time is taken from the curve and used in the equations below. By using the equations, the switching signals are obtained.

$$
\begin{aligned}
Q_{0}(t) & =V_{\text {ref }}(t) \bmod 2 \\
Q_{1}(t) & =\left(\frac{V_{\text {ref }}(t)-\left(V_{\text {ref }}(t) \bmod 2\right)}{2}\right) \bmod 2 .
\end{aligned}
$$

These switching equations can be generalized and the general switching function related to the level module number is defined as:

$$
Q_{(k-1)}(t)=\left(\frac{V_{r e f}(t)-\left(V_{r e f}(t) \bmod 2^{(k-1)}\right)}{2^{(k-1)}}\right) \bmod 2 .
$$

By using equation (14), the switching signals are obtained for the proposed multilevel inverter structure including four

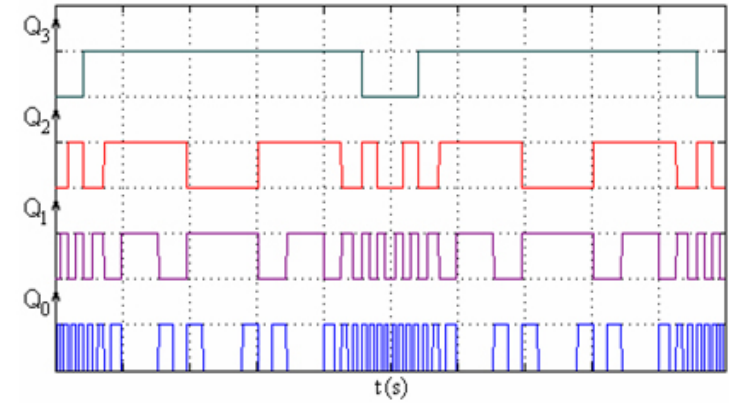

Fig. 5. Switching signals in the proposed multilevel inverter including four level modules.

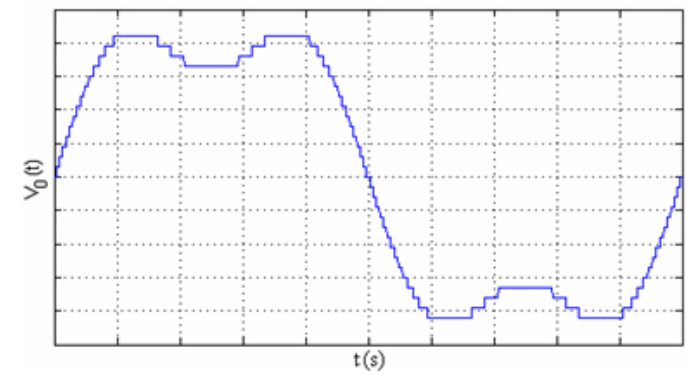

Fig. 6. Output voltage of the proposed multilevel inverter including four level modules.

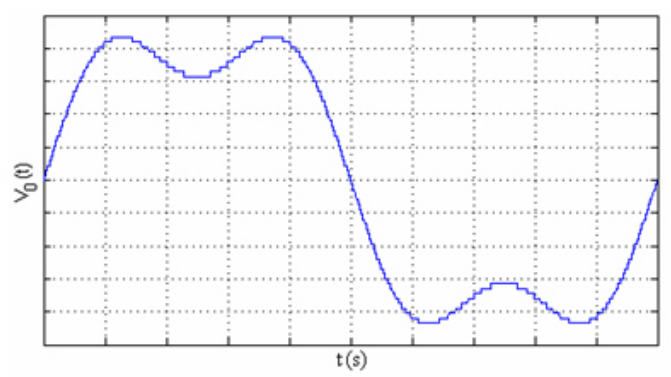

Fig. 7. Output voltage of the proposed multilevel inverter including five level modules.

level modules. Therefore, the reference output voltage wave in Fig.4 is achieved. The switching signals and the simulated output voltage wave are given in Fig.5 and Fig.6 respectively.

It can be seen from Fig.6 that the output voltage of the proposed multilevel inverter is similar to the reference voltage wave.

By increasing the level module number, the shape of output voltage gradually converges to the reference output voltage wave. The output voltages of the proposed inverter structure including five and six level modules are illustrated in Fig.7 and Fig.8, respectively.

\section{Simulation Results}

The proposed inverter structure is simulated for various specific functions. First, the amplitude and degree of harmonic components in the output voltage are determined. According to the required harmonic components, the reference voltage functions are constituted and the switching signals are obtained.

The harmonic components of the reference signals related to the fundamental component are given in Fig.9. The peak 


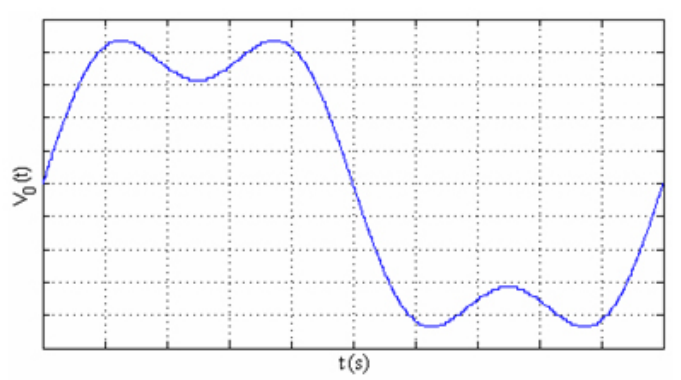

Fig. 8. Output voltage of the proposed multilevel inverter including six level modules.

voltage of the fundamental harmonic component $\left(V_{f}\right)$ is taken as $31 \mathrm{~V}$.

According to the reference functions, the proposed inverter is simulated and simulation results of the output voltage waves are illustrated in Fig.10. The THD values are also calculated for given functions. The simulation results are given in Table 2 together with the experimental results.

\section{EXPERIMENTAL RESULTS}

For verifying the validity of the proposed inverter, a prototype was designed and manufactured. A photograph of the proposed multilevel inverter prototype is shown in Fig.11. The prototype consists of an H-Bridge module and six level modules. So, a maximum 127 output levels can be obtained from the experimental set up. A total of 16 power mosfets (IRFP460, 500V, 20A) are used in the inverter structure. The switching signals are determined by a PIC18F452 microprocessor. All of the simulated specific functions are realized by the proposed inverter structure.

According to the switching angles, the multilevel inverter is switched at certain angles and output voltages with the required harmonic components are obtained. The output voltage waveforms of given functions are shown in Fig.12.

The harmonic components of output voltage forms are measured by a harmonic analyzer and the harmonic spectrums are found. Each harmonic spectrum is given in Fig.12.

It can be seen from Fig.10 and Fig.12 that simulation and experimental results of output voltage waves obtained using the reference signals in Fig.9 are quite similar.

The THD values of the output voltage waves are also measured using the harmonic analyzer. The experimental results are given in Table 2 together with the simulation results.

TABLE II

Total Harmonic Distortion (ThD) Values Of Output Voltage WAVES

\begin{tabular}{c|c|c|c|c}
\hline \multicolumn{5}{c}{ Total Harmonic Distortion (THD) (\%) } \\
\hline Functions & (a) & (b) & (c) & (d) \\
\hline Simulation & 41.46 & 32.32 & 65.44 & 32.33 \\
\hline Experimental & 41.04 & 31.96 & 64.79 & 31.97 \\
\hline
\end{tabular}

It can be seen from Table 2 that simulations and experimental studies give similar results in respect to the THD values.

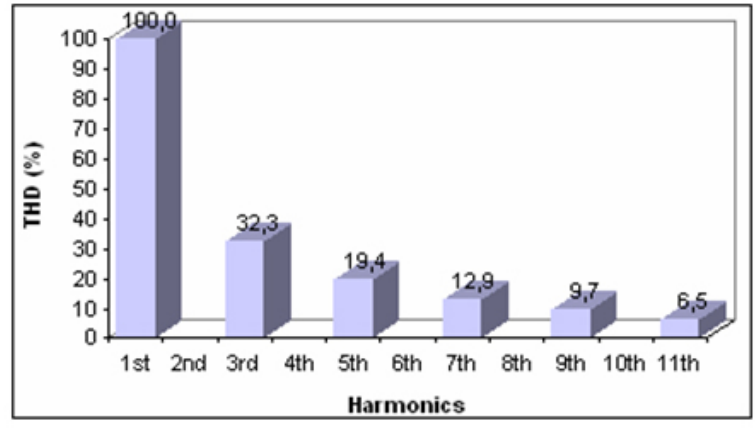

(a) Function a

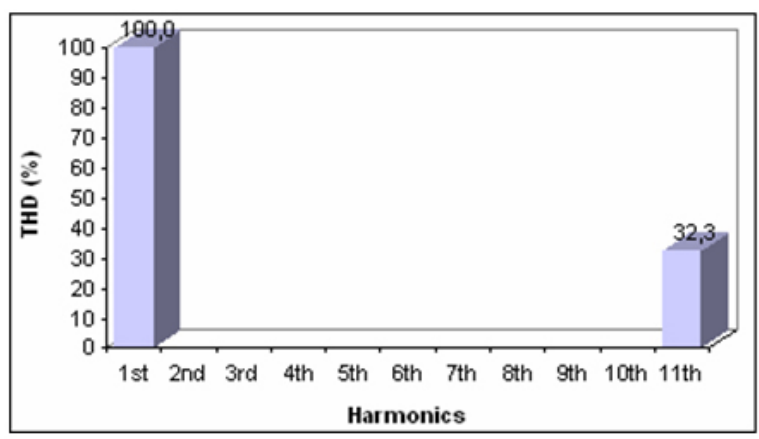

(b) Function b

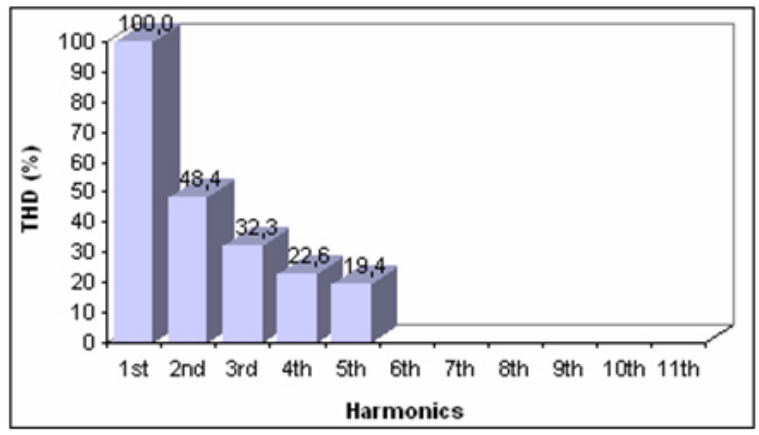

(c) Function c

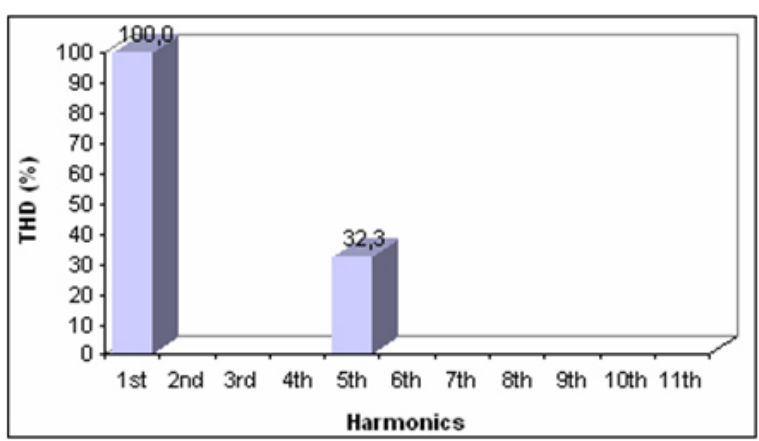

(d) Function d

Fig. 9. Harmonic components of the reference signals related to the fundamental component.

\section{CONCLUSIONS}

A single phase multilevel inverter structure for using as a voltage harmonic source has been introduced in this paper. First, the inverter structure and the switching strategy were explained. To obtain an output voltage with a harmonic content, first, the required harmonic components were determined 


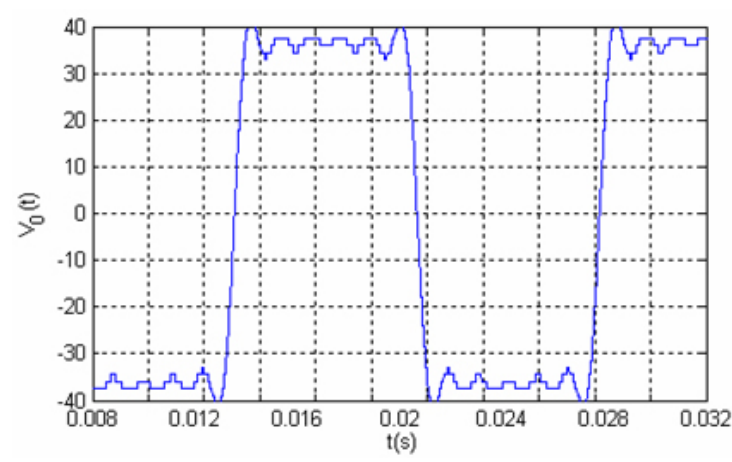

(a) Function a

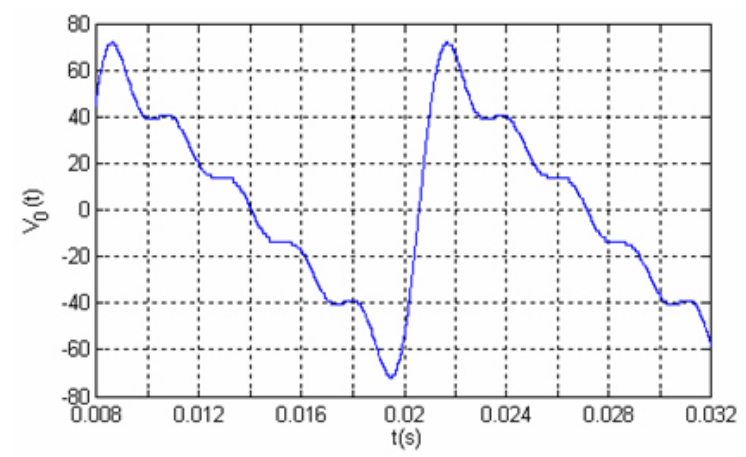

(c) Function c

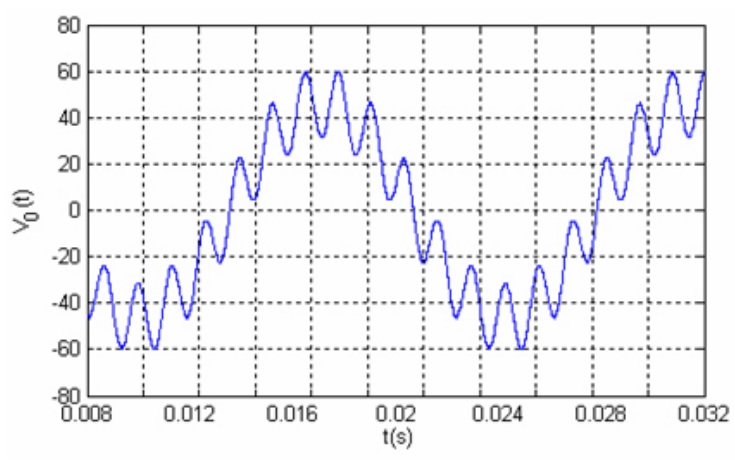

(b) Function b

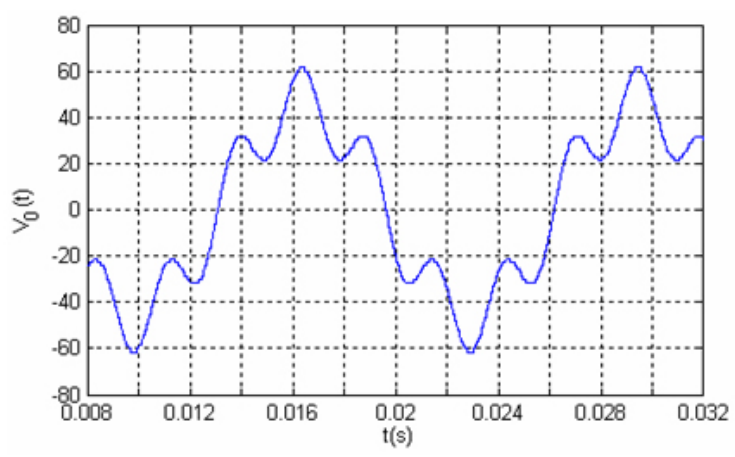

(d) Function d

Fig. 10. Simulation results of output voltage $\left(V_{o}\right)$ with the required harmonic components in the proposed inverter.

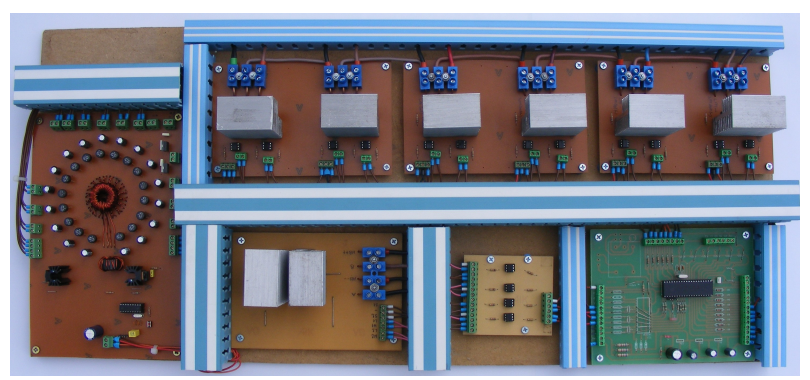

Fig. 11. Photograph of the proposed multilevel inverter prototype.

and the switching signals were obtained. The proposed inverter structure was simulated for various functions and simulation results were given. The simulated functions were realized by the proposed inverter structure. Experimental output voltage waves and the harmonic spectrums were given. The THD values of the output voltage waves were also measured. The results of the study are summarized as follows:

1) The ease of expansion for the proposed multilevel inverter system makes it easy to increase the number of output levels. By adding two switching elements to the proposed system, the output level $(n)$ is changed as $2 n+1$.

2) A simple method is improved for calculating the switching angles, so that they can be easily obtained by using the formula for multilevel output voltage waves.

3) The proposed inverter topology generates a high-quality output voltage waveform.

4) The proposed structure also produces the required har- monic components on the output voltage. This feature makes it possible for the inverter to be used as a voltage harmonic source.

5) For obtaining output voltage with a required harmonic content, the switching equations are improved for finding the switching signals and a generalized formula related to the level module number is obtained.

6) It can be seen that shape of output voltage gradually converges to the reference output voltage wave by increasing the level module number.

7) Through simulations, output voltage waves are obtained for the given reference functions with the required specific harmonic components.

8) The validity of the proposed method is verified by experimental studies. The results show that the proposed inverter gives perfectly suitable results for obtaining output voltage waves with a required harmonic content.

9) The experimental and simulation results are quite similar. This demonstrates that performance predictions can be made easily for various harmonic components by means of a simulation study.

These results show that the proposed multilevel inverter structure gives perfectly suitable results for producing the required waveforms. Output voltages with low harmonic content can be obtained. In addition, output voltages with the required harmonic components can be produced by this structure. Therefore the inverter can be used as a voltage harmonic source in various applications. For instance, it can be used to research harmonic effects on transformers, induction machines, capacitors and transmission line models. Another 


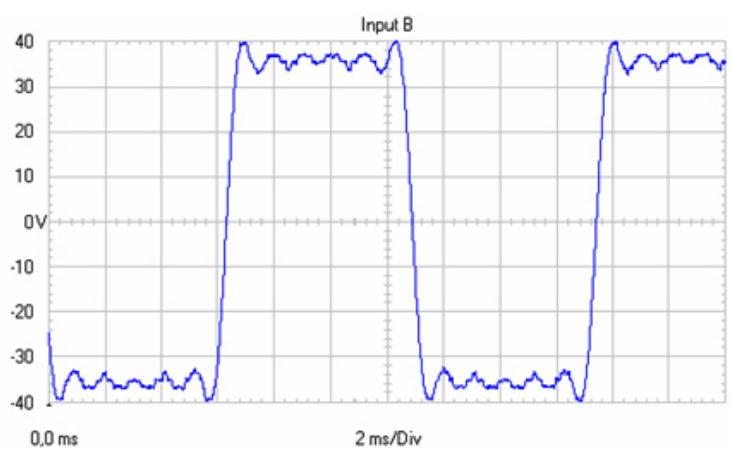

(a)

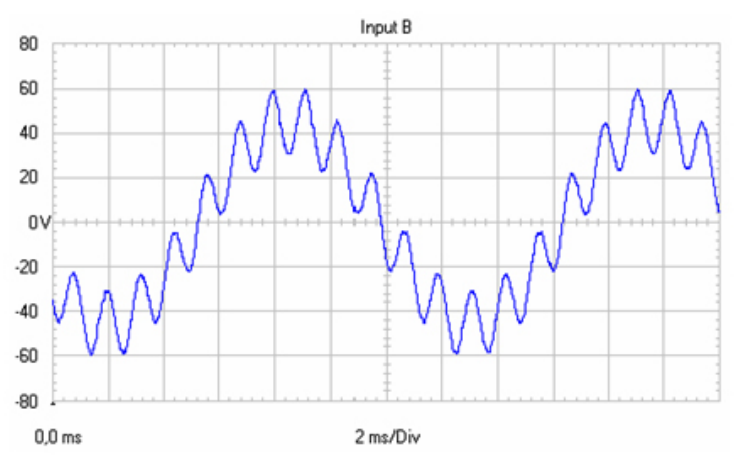

(b)

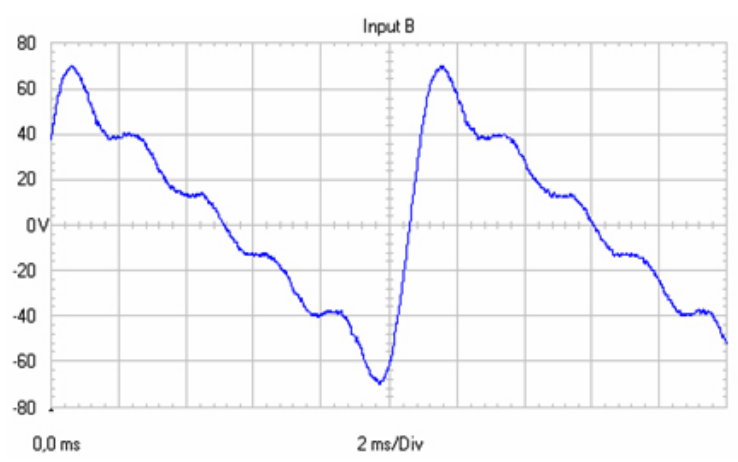

(c)

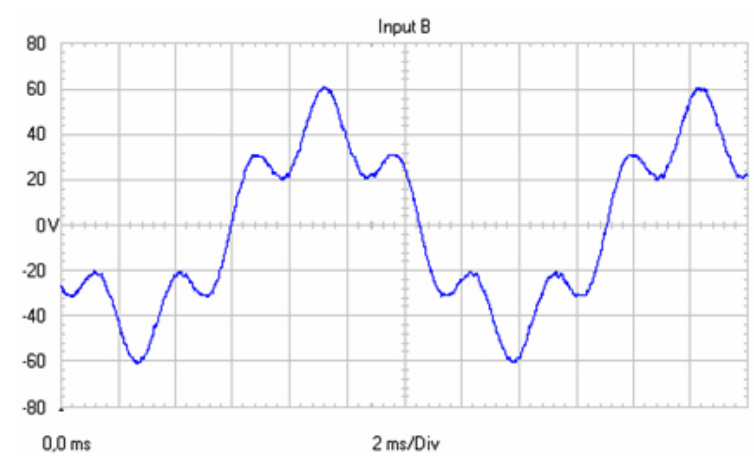

(d)

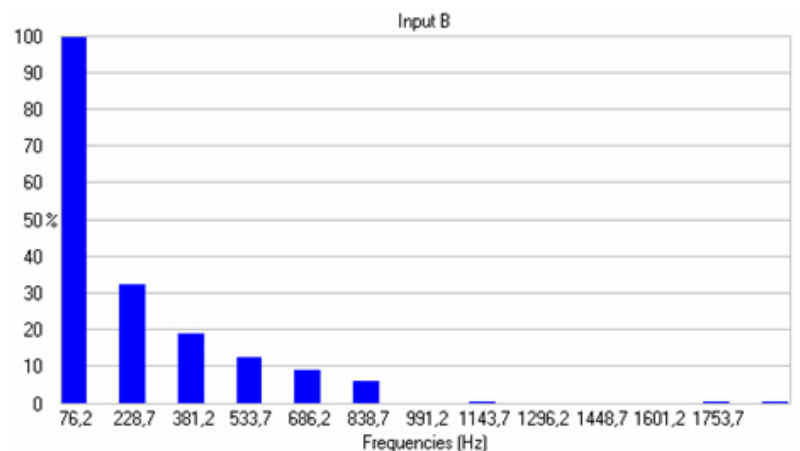

(e)

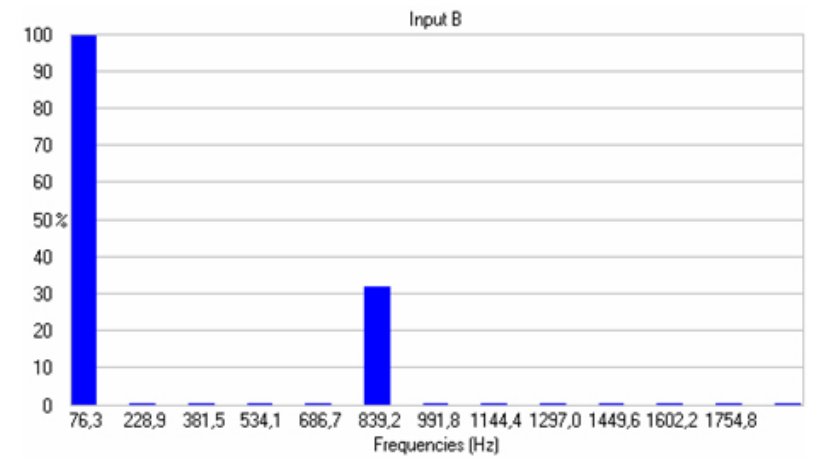

(f)

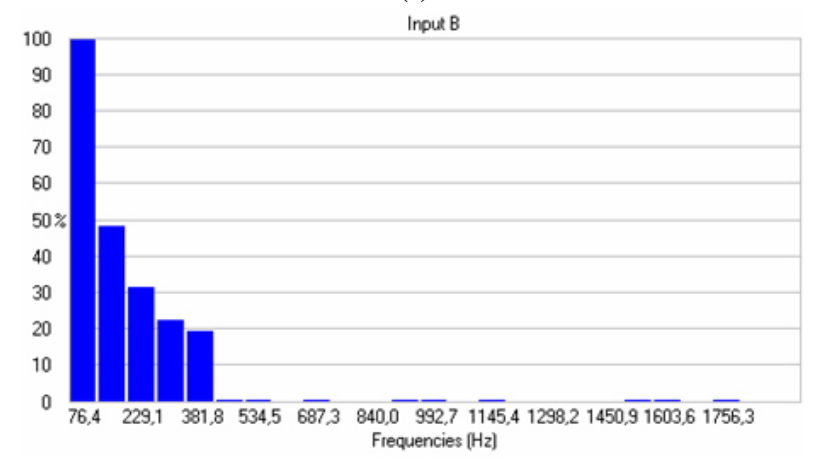

(g)

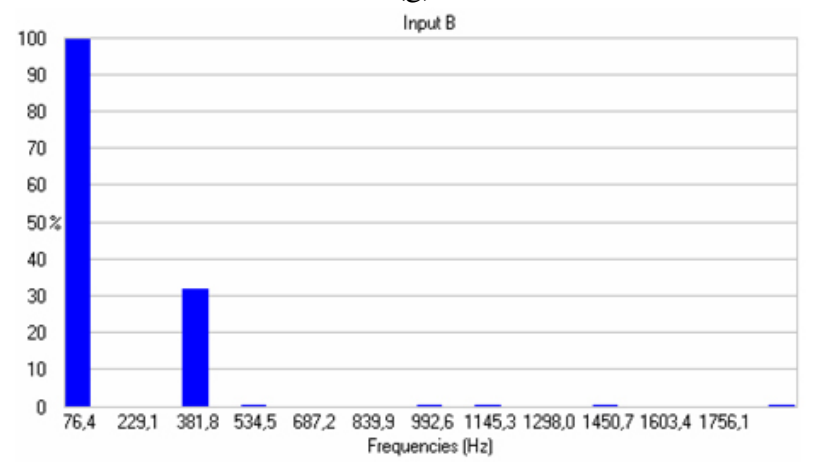

(h)

Fig. 12. Experimental results of output voltage $\left(V_{o}\right)$ with required harmonic components and harmonic spectrums in the proposed inverter (a)-(e) Function a, (b)-(f) Function b, (c)-(g) Function c, (d)-(h) Function d. 
noteworthy implementation area for this structure is voltage active filter applications. It is thought that the proposed structure will be used as a voltage active filter in future studies.

\section{REFERENCES}

[1] W.S. Oh, S.K. Han, S.W. Choi. G.W. Moon, "Three phase three-level PWM switched voltage source inverter with zero neutral point potential," IEEE Trans. on Power Electronics, Vol. 21 No. 5, pp. 1320-1327, Sep. 2006.

[2] J. Rodriguez, J.-S. Lai, and F. Z. Peng, "Multilevel inverters: A survey of topologies, controls and applications," IEEE Trans. Ind. Electron., Vol. 49, No. 4, pp. 724-738, Aug. 2002.

[3] J.S. Lai and F. Z. Peng, "Multilevel converters-a new breed of power converters," IEEE Trans. Ind. Appl., Vol. 32, No. 3, pp. 509-517, May/Jun. 1996.

[4] F. Z. Peng, "A generalized multilevel inverter topology with self voltage balancing," IEEE Trans. Ind. Appl., Vol. 37, No. 2, pp. 611-618, Mar./Apr. 2001.

[5] B.R. Lin, "Analysis and implementation of a three-level PWM rectifier/inverter," IEEE Trans. Aerosp. Electron. Syst., Vol. 36, No. 3, pp. 948-956, Jul. 2000.

[6] C. Hochgraf, R. Lasseter, D. Divan, and T. A. Lipo, "Comparison of multilevel inverters for static Var compensation," Proc. IEEE Conf. Ind. Appl. Soc., Vol. 2, pp. 921-928, Oct. 1994.

[7] A. Nabae, I. Takahashi, and H. Akagi, "A new neutral-point clamped PWM inverter," IEEE Trans. Ind. Appl., Vol. IA-17, No.5, pp. 518-523, Sep./Oct. 1981.

[8] T. A. Meynard and H. Foch, "Multi-level conversion: High voltage choppers and voltage-source inverters," Proc. Power Electron. Spec. Conf., Vol. 1, pp. 397-403, 1992.

[9] M. Marchesoni, M. Mazzucchelli, and S. Tenconi, "A non conventional power converter for plasma stabilization," Proc. IEEE Power Electronics Soc. Conf., pp. 122-129, 1998.

[10] F.S. Kang, S.J. Park, S.E. Cho, C.U. Kim, T. Ise, "Multilevel PWM inverters suitable for the use of stand-alone photovoltaic power systems," IEEE Transactions on Energy Conversion, Vol. 20, No. 4, pp. 906-915, Dec. 2005.

[11] E.Beser, B.Arifoglu, S.Camur, E.Kandemir Beser, "A novel design and application of a single phase multilevel inverter," International Review of Electrical Engineering (IREE), Vol. 4 No. 1, pp. 7-13, Feb. 2009.

[12] S. Çamur , B. Arifoğlu, E. Beşer, E. Kandemir Beşer, "Design and application of a novel structure and topology for single-phase five-level inverter," Wseas Transactions on Electronics, Vol. 3, No. 11, pp.543549, Nov. 2006.

[13] S.J. Park, F.S. Kang, M.H. Lee, C. Kim, "A new single-phase fivelevel PWM inverter employing a deadbeat control scheme," IEEE Transactions on Power Electronics, Vol. 18 No. 3, pp. 831-843, May 2003.

[14] T.F. Wu, H.S. Nien, C.L. Shen, T.M. Chen, "A single-phase inverter system PV power injection and active power filtering with nonlinear inductor consideration," IEEE Transactions on Industry Applications, Vol. 41, No. 4, pp. 1075-1083, Jul./Aug. 2005.

[15] S.Çamur, B.Arifoğlu, E.Beşer, E.Kandemir Beşer, "Harmonic analysis of an improved single phase five level inverter," Wseas Transactions on Power System, Vol. 1, No.2, pp 387-392, Feb. 2006.

[16] V. Yousefzadeh, D. Maksimovic, Q. Li, "A zero voltage switching singlephase inverter using hybrid pulse-width modulation technique," 35th Annual IEEE Power Electronics Specialists Conference, Germany, 2004.

[17] K.K Shyu, M.J. Yang, J.H. Hong, B.H. Lin, "Automatic voltage regulator using a novel phase-shifted PWM single-phase inverter," The 30th Annual Conference of the IEEE Industrial Electronics Society, Korea, 2004.
[18] B.R. Lin, C.H. Huang. "Single-phase capacitors clamped inverter with simple structure," ISCAS, 2004.

[19] T.H. Abdelhamid, J.Y. Madouh, "Advanced static Var compensator using a new topology of multilevel inverters energized from non-equal dc sources," Power and Energy Society General Meeting - Conversion and Delivery of Electrical Energy in the 21st Century, Jul. 2008.

[20] E. Beser, S. Camur, B. Arifoglu, E. Kandemir Beser, "Design and application of a novel structure and topology for multilevel inverter," 2008 International Symposium On Power Electronics, Electrical Drives, Automation and Motion, Vol.1-3, pp. 969-974, Jun. 2008.

[21] M.E.Ahmed, S.Mekhilef, "Design and implementation of a multilevel three-Phase inverter with less switches and low output voltage distortion," Journal of Power Electronics, Vol.9, No.4, pp.593-603, Jul. 2009.

[22] S. Daher, J.Schmid, F.L.M.Antunes, "Multilevel inverter topologies for stand-alone pv systems," IEEE Transactions on Industrial Electronics, Vol.55, No.7, pp. 2703-2712, Jul. 2008.

[23] N.V. Nho, M.J.Youn, "A unified carrier based PWM method in multilevel inverters," Journal of Power Electronics, Vol.5, No.2, pp. 142-150, Apr. 2005.

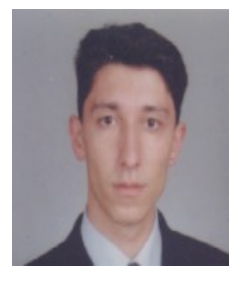

Ersoy Beser was born in Kocaeli, Turkey, on March 23, 1977. He received the B.S. degree, the M.S. degree and the Ph.D. degree in Electrical Engineering from Kocaeli University, Kocaeli, Turkey, in 2000, 2004 and 2009 respectively. He has been a Research Assistant with the Department of Electrical Engineering, Kocaeli University since 2000 . His research interests include power electronics, multilevel inverters, electrical machines, motor control and microprocessors.

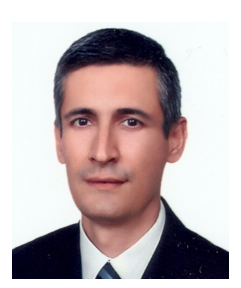

Birol Arifoglu was born in Ksanti, Greece, on June 5, 1968. He received the B.S. degree in Electrical Engineering from Yildiz University, Istanbul, Turkey, in 1989, the M.S. degree from Istanbul Technical University, Istanbul, Turkey, in 1993 and the Ph.D. degree from Kocaeli University, Kocaeli, Turkey, in 1998. Currently, he is an Assistant Professor with the Department of Electrical Engineering, Kocaeli University. His research interests are in the areas of power electronics, dc-dc converters, inverters, automatic control and applications, PLC and SCADA applications, wind energy and industrial electronics and applications.

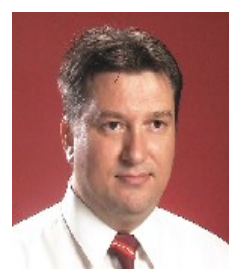

Sabri Camur was born in Adapazari, Turkey, on March 14, 1965. He received the B.S. degree and the M.S. degree in Electrical Engineering from Yildiz University, Istanbul, Turkey, in 1989 and 1991, respectively, and the Ph.D. degree from Kocaeli University, Kocaeli, Turkey, in 1998. Currently, he is an Assistant Professor with the Department of Electrical Engineering, Kocaeli University. His research interests include power electronics, multilevel inverters, electrical machines, design and control of electrical machines, reactive power compensation, solar energy and applications, electronics and industrial electronics.

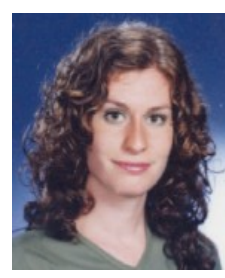

Esra Kandemir Beser was born in Kocaeli, Turkey, on June 10, 1980. She received the B.S. degree and the M.S. degree in Electrical Engineering from Kocaeli University, Kocaeli, Turkey, in 2002 and 2004, respectively. She has been a Research Assistant with the Department of Electrical Engineering, Kocaeli University since 2002. Her research interests include power electronics, multilevel inverters, electrical machines, brushless dc motors and drives and motor control. 